\title{
Catalytic Ring Hydrogenation of Benzoic Acid with Supported Transition Metal Catalysts in $\mathrm{scCO}_{2}$
}

\author{
Hongjun Wang ${ }^{1,2}$ and Fengyu Zhao ${ }^{1, *}$ \\ 1 State Key Laboratory of Electroanalytical Chemistry, Changchun Institute of Applied Chemistry, \\ Chinese Academy of Sciences, Changchun 130022, P. R. China; E-mail: zhaofy@ ciac.jl.cn \\ 2 School of Chemical Engineering, Changchun University of Technology, Changchun 130012, \\ P. R.China; E-mail: whj@ciac.jl.cn \\ * Author to whom correspondence should be addressed: Tel \& Fax: +86-431-8526-2410; \\ E-mail: zhaofy@ciac.j1.cn
}

Received: 23 April 2007; in Revised Form: 10 May 2007 / Accepted: 12 May 2007 /

Published: 12 July 2007

\begin{abstract}
The ring hydrogenation of benzoic acid to cyclohexanecarboxylic acid over charcoal-supported transition metal catalysts in supercritical $\mathrm{CO}_{2}$ medium has been studied in the present work. The cyclohexanecarboxylic acid can be produced efficiently in supercritical $\mathrm{CO}_{2}$ at the low reaction temperature of $323 \mathrm{~K}$. The presence of $\mathrm{CO}_{2}$ increases the reaction rate and several parameters have been discussed.
\end{abstract}

Keywords: Hydrogenation; benzoic acid; cyclohexanecarboxylic acid; $\mathrm{scCO}_{2}$

\section{Introduction}

Hydrogenation of benzoic acid (BA) is an important industrial reaction as its product cyclohexanecarboxylic acid (CCA) is a very important and excellent chemical or pharmaceutical intermediate, which have been used in the synthesis of 1-hydroxy cyclohexyl phenyl ketone and praziquantel, and its derivatives, such as trans-4-isopropylcyclohexyl acid and cyclohexylmethyl carbamate, $\mathrm{N}$-(cyclohexylcarbonyl)-D-phenylalanine are important intermediates for organic synthesis in fine chemical industries [1,2]. The production of cyclohexanecarboxylic acid by catalytic hydrogenation of benzoic acid is well known, but it endures some disadvantages in both technical and economic aspects, which inhibit their application on a commercial scale. Cyclohexanecarboxylic acid can be produced from hydrogenation of molten benzoic acid without any solvent, but the reaction 
temperature and pressure are relatively high [3]. Practically, $\mathrm{Pd} / \mathrm{C}$ catalyst was used to produce cyclohexanecarboxylic acid from the hydrogenation of benzoic acid at high temperature of $423 \mathrm{~K}$ and high $\mathrm{H}_{2}$ pressure of $15 \mathrm{MPa}$ [4-6]. Furthermore, organic solvents used in the process usually bring some drawbacks. For example, when methanol was used as solvent in the hydrogenation of benzoic acid, ester was usually formed and which should be removed carefully from the desired product; The higher alcoholic solvents are not only relatively difficult to separate from product but also expensive [7]; Acidic solvents, such as acetic acid, bring a serious waste disposal problem for it is difficult to recover; Basic solvents, like aqueous alkali, cause decarboxylation and thus give relatively low yield to the desired product [8,9]. Recently, much effort has been paid to avoid using organic solvents, and supercritical fluids are used as a replacement in various chemical reactions [10-13]. Especially, supercritical carbon dioxide $\left(\mathrm{scCO}_{2}\right)$ as an environmentally benign solvent for organic synthetic reactions is currently receiving much attention. For its physicochemical properties may be manipulated by changing the pressure and temperature slightly, $\mathrm{scCO}_{2}$ has been widely used as a green reaction medium in hydrogenation reactions [14-19]. It was reported that the hydrogenation of unsaturated aldehydes could be performed successfully in $\mathrm{scCO}_{2}$ with a significant improvements in activity and product selectivity [15-19]. The hydrogenation of butynediol in $\mathrm{scCO}_{2}$ was reported to be promoted by a steel-stainless reactor wall in the absence of any catalyst [20,21]. Rode et al. [22] reported that $\mathrm{Rh} / \mathrm{C}$ was highly active for the ring hydrogenation of phenol and cresols in $\mathrm{scCO}_{2}$.

The present paper reports the ring hydrogenation of benzoic acid with transition metals supported on carbon under low reaction temperature in $\mathrm{scCO}_{2}$. The solubility of benzoic acid in $\mathrm{scCO}_{2}$ and phase behavior was inspected, and several reaction parameters were discussed.

\section{Experimental}

\subsection{Hydrogenation studies}

The transition metal catalysts were purchased from Wako Pure Chemical Industries, Ltd., which were reduced at $573 \mathrm{~K}$ for $2 \mathrm{~h}$ with hydrogen gas before reaction. The hydrogenation reactions were carried out in a $50 \mathrm{~mL}$ stainless steel autoclave. A certain amount of catalyst and the reactant, benzoic acid was charged into the reactor and the reactor was flushed with $\mathrm{N}_{2}$ or $2.0 \mathrm{MPa} \mathrm{CO}_{2}$ three times to remove the air. The reactor was then heated up to the desired temperature and $\mathrm{H}_{2}$ and compressed liquid $\mathrm{CO}_{2}$ were introduced with a high-pressure liquid pump. The reaction runs were conducted while stirring with a magnetic stirrer. At the end of the reaction, the autoclave was cooled to room temperature then depressurized carefully by backpressure regulator. The composition of reaction mixture was analyzed by a gas chromatograph using a flame ionization detector.

\subsection{Phase behavior observation}

A viewing cell (internal volume $80 \mathrm{ml}$ ) was used to observe the phase behavior of reactants in $\mathrm{scCO}_{2}$, it is equipped with windows and connected to a temperature-controlled system. A certain amount of substrate was added into the cell, and then the cell was flushed with $0.5 \mathrm{MPa} \mathrm{CO}_{2}$ twice. After the cell was heated to $323 \mathrm{~K}$ (reaction temperature), $\mathrm{CO}_{2}$ was introduced into it and the stirring was started. When the pressure reached a certain value, the stirring was continued for 3-5 min and then 
stopped; the state of the mixture including the substrate and $\mathrm{CO}_{2}$ was visually inspected. This examination was made at intervals of 0.2-0.5 MPa to determine the pressure at which the substrate was completely dissolved into $\mathrm{CO}_{2}$, forming a single phase. Then, the pressure was decreased in a similar way to determine the pressure at which droplets appeared (dew point), changing into a two-phase mixture. The pressures determined at increasing and decreasing pressures were less than $0.3 \mathrm{MPa}$ different, and the average value of the two pressures determined was used. Those observations were used to estimate the solubility of BA, CCA and the mixture of them in $\mathrm{CO}_{2}$ at different pressures.

\section{Results and discussion}

\subsection{Hydrogenations in $\mathrm{ScCO}_{2}$ with different catalysts}

The catalytic performance of several transition metal catalysts for hydrogenation of benzoic acid in $\mathrm{scCO}_{2}$ are compared in Table 1, Carbon-supported transition metal catalysts such as $\mathrm{Pd} / \mathrm{C}, \mathrm{Rh} / \mathrm{C}, \mathrm{Ru} / \mathrm{C}$ and $\mathrm{Pt} / \mathrm{C}$, were active for hydrogenation of benzoic acid to cyclohexanecarboxylic acid at the lower temperature of $353 \mathrm{~K}$ in $\mathrm{scCO}_{2}$. Under the reaction conditions used, benzoic acid was almost completely converted with $\mathrm{Rh} / \mathrm{C}$ catalyst to produce cyclohexanecarboxylic acid as an isolated product with $100 \%$ selectivity. The activity order of these transition metal catalysts is $\mathrm{Rh} / \mathrm{C}>\mathrm{Ru} / \mathrm{C}>\mathrm{Pt} / \mathrm{C}>$ $\mathrm{Pd} / \mathrm{C}$. While, it was reported in the literature that $\mathrm{Pd} / \mathrm{C}$ is a suitable catalyst for benzoic acid hydrogenation in three-phases of gas $\left(\mathrm{H}_{2}\right)$-liquid (molten benzoic acid)-solid (catalyst) at temperature above $453 \mathrm{~K}$ [6].

Table 1. Results of benzoic acid hydrogenation with supported transition metal catalysts in $\mathrm{scCO}_{2}$.

\begin{tabular}{cc}
\hline Catalysts & Product Yield (\%) \\
\hline $\mathrm{Pd} / \mathrm{C}$ & 3.3 \\
$\mathrm{Pt} / \mathrm{C}$ & 3.4 \\
$\mathrm{Ru} / \mathrm{C}$ & 68.3 \\
$\mathrm{Rh} / \mathrm{C}$ & 99.1
\end{tabular}

Reaction conditions: $\mathrm{H}_{2}$ pressure, $10 \mathrm{MPa}$; $\mathrm{CO}_{2}$ pressure, $10 \mathrm{MPa}$; reaction temperature, $323 \mathrm{~K}$; reaction time, $3 \mathrm{~h}$.

\subsection{Effects of $\mathrm{CO}_{2}$ and $\mathrm{H}_{2}$ pressures}

Table 2 shows that the yield of CCA is dependent on $\mathrm{CO}_{2}$ pressure. The hydrogenations were carried out in the presence of $2 \mathrm{MPa} \mathrm{H}_{2}$ at $323 \mathrm{~K}$ for $3 \mathrm{~h}$, as can be seen from the data in the Table 2 the yield of $\mathrm{CCA}$ increases with increasing $\mathrm{CO}_{2}$ pressure from 0 to $10 \mathrm{MPa}$, indicating that the presence of $\mathrm{CO}_{2}$ can improve the reaction rate. Usually, a dilution effect (negative) should exist by introducing large amount of $\mathrm{CO}_{2}$, while the reaction conversion did not decrease but increased slightly with increasing $\mathrm{CO}_{2}$ pressure, suggesting that the positive effect should exist and which is dominant and retards the dilution effects of introducing large amount of $\mathrm{CO}_{2}$. This may be attribute to several 
positive factors (1) enhancing hydrogen concentration; (2) phase behavior; (3) the molecule interaction among substrate, catalyst and $\mathrm{CO}_{2}$ molecules [12-14].

Table 2. Influence of $\mathrm{CO}_{2}$ pressure on the hydrogenation of benzoic acid over $5 \% \mathrm{Rh} / \mathrm{C}$ catalyst in $\mathrm{scCO}_{2}$.

\begin{tabular}{ccc}
\hline $\mathrm{H}_{2}$ pressure $(\mathrm{MPa})$ & $\mathrm{CO}_{2}$ pressure $(\mathrm{MPa})$ & Yield of CCA $(\%)$ \\
\hline 2 & 0 & 24.6 \\
2 & 4 & 28.4 \\
2 & 8 & 32.9 \\
2 & 10 & 39.6
\end{tabular}

Reaction conditions: temperature, $323 \mathrm{~K}$; reaction time, $3 \mathrm{~h}$; benzoic acid, $8.2 \mathrm{mmol}$.

The influence of hydrogen pressure has been studied for benzoic acid hydrogenation in the presence of $10 \mathrm{MPa} \mathrm{CO}_{2}$ as shown in Figure 1. The conversion increased linearly with increasing $\mathrm{H}_{2}$ pressure from 2 to $10 \mathrm{MPa}$ and a high conversion of $99.1 \%$ was achieved at $\mathrm{H}_{2}$ pressure of $10 \mathrm{MPa}$, while it is about $39.6 \%$ at $2 \mathrm{MPa}$, suggesting the reaction rate depends on the concentration of hydrogen largely in $\mathrm{scCO}_{2}$.

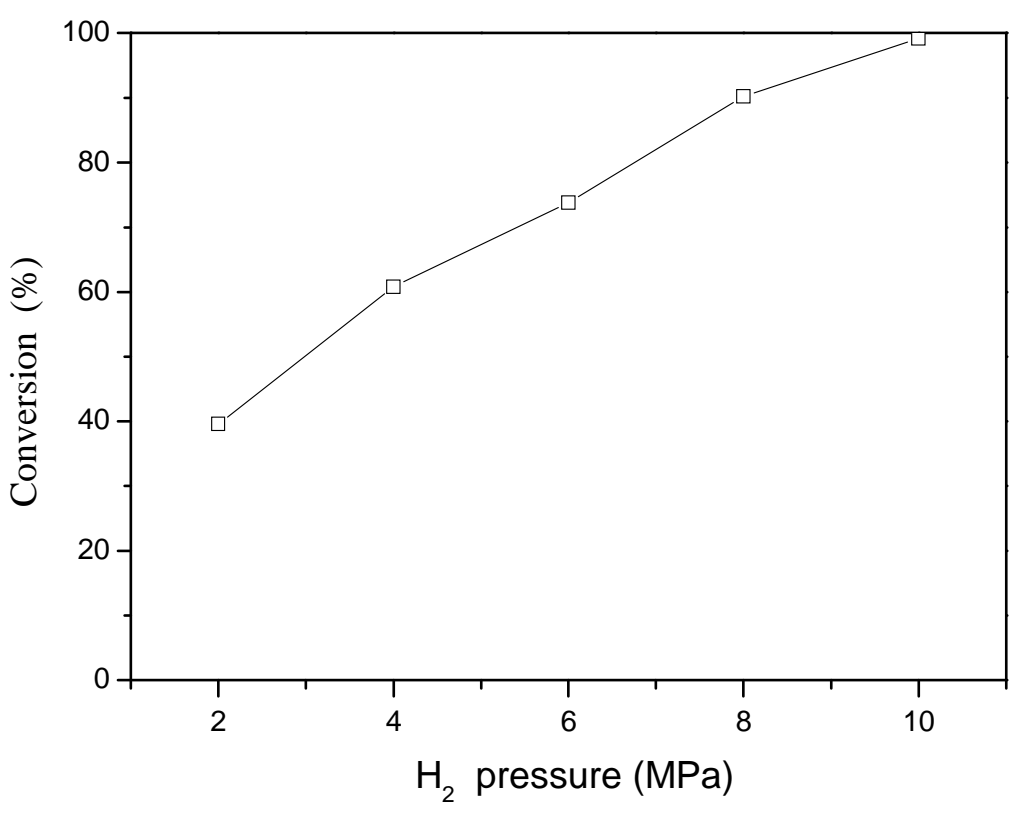

Figure 1. Influence of $\mathrm{H}_{2}$ pressure on hydrogenation of benzoic acid over $\mathrm{Rh} / \mathrm{C}$ catalyst in the presence of $10 \mathrm{MPa} \mathrm{CO}_{2}$. Reaction conditions: benzoic acid, $8.2 \mathrm{mmol}$; catalyst, $\mathrm{Rh} / \mathrm{C} 0.05 \mathrm{~g}$; temperature, $323 \mathrm{~K}$; reaction time, $3 \mathrm{~h}$.

\subsection{Solubility and phase behavior in $\mathrm{scCO}_{2}$}

For confirming whether the reaction in $\mathrm{scCO}_{2}$ is taking place homogeneously in a single phase or heterogeneously in two or more phases, phase behavior observation and solubility estimation have been carried out with a high-pressure view-cell. Figure 2 shows the solubilities of benzoic acid, cyclohexanecarboxylic acid and the mixture of them at $50{ }^{\circ} \mathrm{C}$. The results indicate that the solubilities 
of these solid substrates increase with increasing $\mathrm{CO}_{2}$ pressure, namely, the higher $\mathrm{CO}_{2}$ pressure, the more solid substrate dissolved. The order of the solubility is cyclohexanecarboxylic acid $>$ the mixture of benzoic acid and cyclohexanecarboxylic acid > benzoic acid. The state of the reaction mixture under different $\mathrm{CO}_{2}$ pressures was observed in the absence of catalyst. At the $\mathrm{CO}_{2}$ pressure below $7 \mathrm{MPa}$, two phases presented as gas $\left(\mathrm{CO}_{2}\right.$ riched gas phase) and solid (benzoic acid) phases for its melting point is $395 \mathrm{~K}$ higher than the reaction temperature of $323 \mathrm{~K}$, the reaction should occur on the interface of the solid (benzoic acid)- solid (catalyst) -gas $\left(\mathrm{H}_{2}\right)$. With increasing $\mathrm{CO}_{2}$ pressure, a part of benzoic acid could dissolve into supercritical $\mathrm{CO}_{2}$ phase. Furthermore, in the presence of catalyst with the formation of cyclohaxanecarboxylic acid (liquid state under the reaction conditions), a part of reactions performed on the interface of liquid-solid. When $\mathrm{CO}_{2}$ was raised up to an assured pressure or with the reaction process deeply, a homogeneous and uniform phase was formed in which all the substrate dissolved into $\mathrm{CO}_{2}$ gas phase. Since the reaction system is not simple, the overall rate of reaction should depend on several factors including the volume of the phases present, the concentration of the reacting species, the activity of catalytic active species and the reaction kinetics in these phases. Further study is needed to explain the results and several chemical and physical factors should be considered.

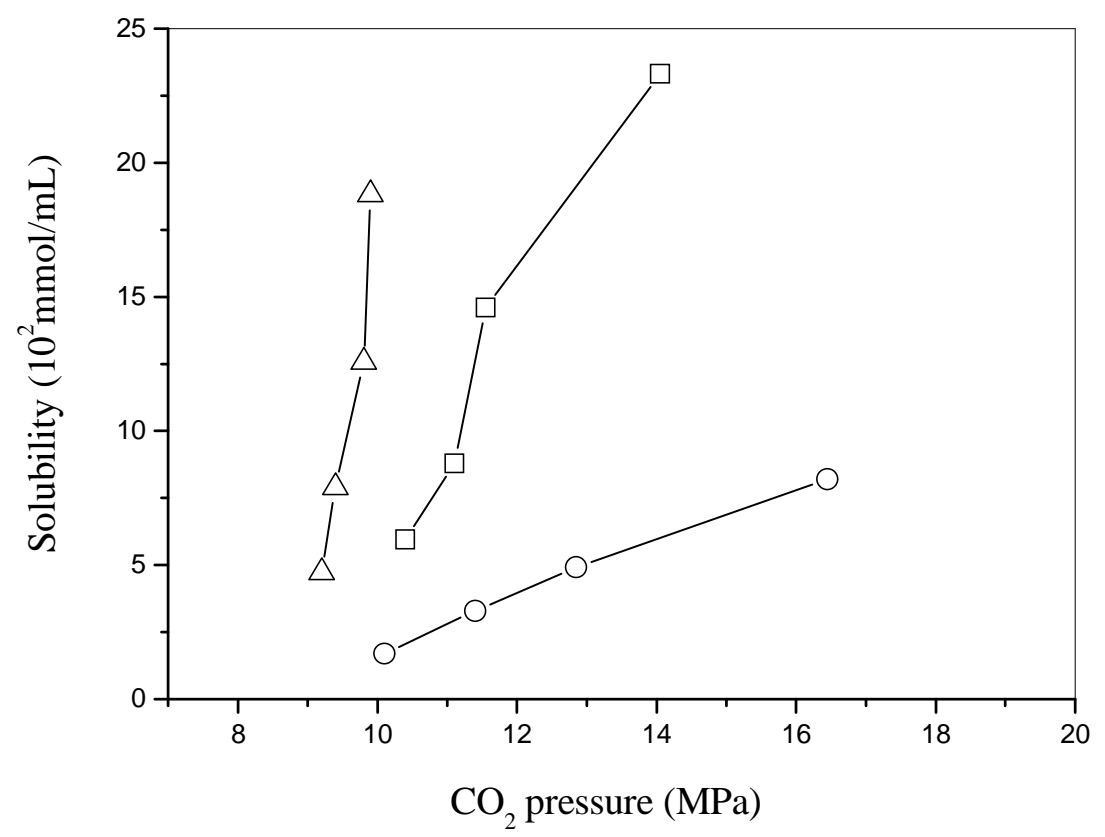

Figure 2. Solubility estimation of benzoic acid, cyclohexanecarboxylic acid and mixture of them in

$\mathrm{CO}_{2}$ at $323 \mathrm{~K}$. $\triangle$ cyclohexanecarboxylic acid; $\square$ the mixture of benzoic acid and cyclohexanecarboxylic acid; $\bigcirc$ benzoic acid.

\subsection{Hydrogenations of several substrates}

The catalytic activity of the $\mathrm{Rh} / \mathrm{C}$ catalysts have been examined for the hydrogenation of phenol, benzoic acid, p-toluic acid and 4-ethylbenzoic acid in $\mathrm{scCO}_{2}$, the results are shown in Table 3. The catalysts are active for hydrogenation of benzene ring at the lower temperature of $323 \mathrm{~K}$ in $\mathrm{scCO}_{2}$. At the pressures of $\mathrm{CO}_{2} 10 \mathrm{MPa}$ and $\mathrm{H}_{2} 4 \mathrm{MPa}$, benzoic acid and phenol were quite reactive and converted to its ring hydrogenation products with a conversion of $95.8 \%$ and $91.8 \%$, respectively; the conversion of 4-ethylbenzoic acid is $56.6 \%$ and $p$-toluic acid is $20.8 \%$ under the same reaction 
conditions. These results indicated the substituent group attached the benzene ring has a significant effect on the reactivity of the ring hydrogenation.

Table 3. Hydrogenation of aromatic compounds over $5 \% \mathrm{Rh} / \mathrm{C}$ at $323 \mathrm{~K}$.

\begin{tabular}{cc}
\hline Reactant & Conversion (\%) \\
\hline Benzoic acid & 95.8 \\
Phenol & 91.8 \\
4-Ethylbenzoic acid & 56.6 \\
p-Toluic acid & 20.8 \\
Reaction conditions: $\mathrm{H}_{2}$ pressure 4 MPa; $\mathrm{CO}_{2}$ pressure $10 \mathrm{MPa}$; reactant $8.2 \mathrm{mmol}$; \\
reaction time $6 \mathrm{~h}$.
\end{tabular}

\section{Conclusions}

Hydrogenation of benzoic acid to cyclohexanecarboxylic acid over several transition metal catalysts under supercritical $\mathrm{CO}_{2}$ medium has been studied. This study demonstrates that ring hydrogenation of benzoic acid can be successfully carried out in $\mathrm{scCO}_{2}$ medium with $\mathrm{Rh} / \mathrm{C}$ catalyst at the low reaction temperature of $323 \mathrm{~K}$, in which without any waste was produced and the catalyst separation from product can be handled easily by simple phase separation. Use of $\mathrm{scCO}_{2}$ as alternative media for hydrogenations promises to overcome some of drawbacks described associated with conventional organic solvents and offers both process and environmental advantages.

\section{Acknowledgments}

The authors gratefully acknowledge to the financial support from the One Hundred Talent Program of CAS.

\section{References}

1. Shinkai, H.; Toi, K.; Kumashiro, I.; Seto, Y.; Fukuma, M.; Dan, K.; Toyoshima, S. Nacylphenylalanines and related compounds. A new class of oral hypoglycemic agents. J. Med. Chem. 1988, 31, 2092-2097.

2. Shinkai, H.; Nishikawa, M.; Sato, Y.; Toi, K.; Kumashiro, I.; Seto, Y.; Fukuma, M.; Dan, K.; Toyoshima, S. N-(cyclohexylcarbony1)-D-phenylalanines and related compounds. A new class of oral hypoglycemic agents. 2. J. Med. Chem. 1989, 32, 1436-1441.

3. Winstrom, L.O.; Snider, O. Cyclohexane carboxylic acid produced by hydrogenation of molten benzoic acid, U. S. Patent, US 3141036/1964.

4. SNIA VISCOSA. Improved process for hydrogenation benzoic acid, Italy Patent, IE 967918/ 1964.

5. SNIA VISCOSA. Improved method for hydrogenation benzoic acid, Italy Patent, IE 1019795/ 1966. 
6. SNIA VISCOSA. Apparatus and method for the hydrogenation of benzoic Acid, Italy Patent, IE $1122162 / 1968$.

7. Yasuhara, Y.; Nishino, M. Method of producing cyclohexane derivatives directly from aromatic hydrocarbons, U.S. Patent, US 4508918/1985.

8. Karl, S.; Klaus, M. Process for the production of alkali salts of cyclohexane carboxylic acid, U.S. Patent, US 976919/1963.

9. Seon, K.D.; Cheol, K.S. Preparation method of cyclohexanecarboxylic acid by hydrogenation of benzoic acid in aqueous solution and cyclohexanecarboxylic acid prepared by the method, K.R. Patent, KR 20030083882/2003.

10. Leitner, W. Supercritical carbon dioxide as a green reaction medium for catalysis. Acc. Chem. Res. 2002, 35, 746-745.

11. Baiker, A. Supercritical fluids in heterogeneous catalysis. Chem. Rev. 1999, 99, 453-473.

12. Jessop, P.G.; Leitner, W.(Eds.) Chemical Synthesis Using Supercritical Fluids, Wiley/VCH, Weinheim, 1999.

13. Grunwaldt, J.D.; Wandeler, R.; Baiker, A. Supercritical fluids in catalysis: opportunities of in situ spectroscopic studies and monitoring phase behaviour. Catal. Rev. Sci. Eng. 2003, 45, 1-96.

14. Leitner, W. Carbon dioxide as a raw material: The synthesis of formic acid and its derivatives from $\mathrm{CO}_{2}$. Angew. Chem. Int. Edit. Engl. 1995, 34, 2207-2221.

15. Zhao, F.; Ikushima, Y.; Chatterjee, M.; Sato, O.; Arai, M. Hydrogenation of an $\alpha, \beta$-unsaturated aldehyde catalyzed with ruthenium complexes with different fluorinated phosphine compounds in supercritical carbon dioxide and conventional organic solvents. J. Supercrit. Fluids. 2003, 27, 65-72.

16. Zhao, F.; Ikushima, Y.; Shirai, M.; Ebina, T.; Arai, M. Influence of electronic state and dispersion of platinum particles on the conversion and selectivity of hydrogenation of an $\alpha, \beta$-unsaturated aldehyde in supercritical carbon dioxide. J. Mol. Catal. A: Chem. 2002, 180, 259-265.

17. Zhao, F.; Ikushima, Y.; Chatterjee, M.; Shirai, M.; Arai, M. An effective and recyclable catalyst for hydrogenation of $\alpha, \beta$-unsaturated aldehydes into saturated aldehydes in supercritical carbon dioxide. Green Chem. 2003, 5, 76-79.

18. Bhanage, B.M.; Ikushima, Y.; Shirai, M.; Arai, M. The selective formation of unsaturated alcohols by hydrogenation of $\alpha, \beta$-unsaturated aldehydes in supercritical carbon dioxide using unpromoted $\mathrm{Pt} / \mathrm{Al}_{2} \mathrm{O}_{3}$ catalyst. Catal. Lett. 1999, 62, 175-177.

19. Zhao, F.; Zhang, R.; Chatterjee, M.; Ikushima, Y. Arai, M. Hydrogenation of nitrobenzene with supported transition metal catalysts in supercritical carbon dioxide. Adv. Synth. Catal. 2004, 346, 661-668.

20. Zhao, F.; Ikushima, Y.; Arai, M. Hydrogenation of 2-butyne-1,4-diol to butane-1,4-diol in supercritical carbon dioxide. Green Chem. 2003, 5, 656-658.

21. Zhao, F.; Ikushima, Y.; Arai, M. Hydrogenation of 2-butyne-1,4-diol in supercritical carbon dioxide promoted by stainless steel reactor wall. Catalysis Today. 2004, 93-95, 439-443.

22. Rode, C.V.; Joshi, U.D.; Sato, O.; Shirai, M. Catalytic ring hydrogenation of phenol under supercritical carbon dioxide. Chem. Commun. 2003, 15, 1960-1961.

(C) 2007 by MDPI (http://www.mdpi.org). Reproduction is permitted for noncommercial purposes. 